\title{
A AMAMENTAÇÃO NA VOZ DE PUÉRPERAS PRIMÍPARAS
}

Cleunir de Fátima Candido De Bortoli', Jésica Fernanda Poplaski, Paula Roberta Balotin

Objetivo: Conhecer as vivências acerca do processo de amamentação, por mulheres primíparas durante o puerpério. Metodologia: Estudo de campo, descritivo de abordagem qualitativa, desenvolvido em uma unidade básica de saúde, com participação de nove puérperas primíparas. Os dados foram coletados por meio da entrevista semiestruturada, orientada pela questão de pesquisa: Como as mulheres primíparas vivenciam o processo de amamentação? E analisados pela técnica de análise de conteúdo temática, pela proposta operativa. Resultados: Entre os desafios que permeiam a amamentação, a pega inicial e os traumas mamilares demonstraram maior relevância. Os prazeres acerca da amamentação, como um momento de reconhecimento entre mãe e filho, um formador de vínculos entre os dois. Conclusões: A orientação profissional adequada obteve efeito positivo na prevenção destes eventos. O enfermeiro se faz muito importante nesta fase, preparando a mulher para todas as adversidades e auxiliando no estabelecimento da amamentação e preservando a durabilidade do aleitamento.

Descritores: Aleitamento materno; Período Pós-parto; Enfermagem.

\section{BREASTFEEDING IN THE VOICE OF PRIMIPARIAN PUERPERAS}

Objective: To know the experiences about the breastfeeding process by primiparous women during the puerperium period. Methodology: Field study, descriptive of a qualitative approach, developed in a basic health unit, with the participation of nine primiparous women. Data were collected through a semistructured, oriented by the research question: How are women primiparean prepared to experience the breastfeeding process? And analyzed by the thematic content analysis technique, by the operational proposal. Results: In between the challenges that permeate breastfeeding, where the initial breastfeeding and mammillary traumas showed greater relevance. The pleasures of breastfeeding, as a moment of recognition between mother and child, forming links between the two. Conclusions: Adequate professional guidance has had a positive effect on the prevention of these events. The nurse becomes very important at this stage, preparing the woman for all adversities and assisting in the establishment of breastfeeding and preserving the durability of breastfeeding.

Descriptors: Breastfeeding; Postpartum period; Nursing.

\section{LAAMAMENTACIÓN EN LA VOZ DE PUERPERAL PRIMÍPARAS}

Objetivo: Conocer las vivencias sobre el proceso de lactancia, por mujeres primiparas durante el puerperio. Metodología: Estudio de campo, descriptivo de abordaje cualitativo, desarrollado en una unidad básica de salud, con participación de nueve puérperas primíparas. Los datos fueron recolectados a través de la entrevista semiestructurada, orientada por la cuestión de investigación: ¿Cómo las mujeres vivenciadas en el proceso de lactancia? Y analizados por la técnica de análisis de contenido temático, por la propuesta operativa. Resultados: Entre los desafíos que alcanzaron una lactancia materna, el establecimiento de la lactancia materna y los traumas mamilares mostraron mayor relevancia. Los placeres de la lactancia, como un momento de reconocimiento entre madre e hijo, un creador de vínculos entre los dos. Conclusiones: La orientación profesional adecuada ha tenido un efecto positivo en la prevención de estos eventos. El enfermero es muy importante en esta fase, preparando a una mujer para todas las adversidades y ayudando en el establecimiento de la lactancia y preservando la durabilidad de la lactancia.

Descriptores: Período postparto; Lactancia materna; Enfermería. 


\section{INTRODUÇÃO}

O puerpério é caracterizado pelo momento que inicia após o parto, que tem duração inexata, mas que habitua variar entre quatro a seis semanas. Compõe um momento em que as modificações locais e sistêmicas na fisiologia da mulher, retornam à situação do estado anterior à gestação(1). Porém, nem todos os sistemas maternos reassumem à condição primitiva, sendo os seios a exceção, pois estes alcançam o desenvolvimento e a diferenciação celular completos nesta fase e não retomam seu estado pré-gravídico(2).

É sabido que o leite materno é essencial em relação ao crescimento e desenvolvimento da criança e que, além da nutrição, contribui no controle das infecções e em outros importantes aspectos fisiológicos maternos. Porém, fatores como a falta de conhecimento da puérpera e da família ou o envolvimento cultural no processo de aleitamento, além da falta de apoio, podem favorecer a um desmame precoce. As informações e orientações corretas ajudam a vencer obstáculos e promover a qualidade da amamentação ${ }^{(3)}$. Neste contexto, as pessoas que estão presentes no cotidiano da mulher, estão fortemente ligadas ao apoio e à manutenção da amamentação. Aspectos culturais e histórico familiar influenciam diretamente nas crenças maternas, na sua compreensão sobre o processo de amamentar, em seus medos e dúvidas ${ }^{(4)}$.

Intervenções educativas em saúde, fornecem subsídios a mulher e possibilitam a ela adotar medidas práticas e mais adequadas em relação a amamentação e consequentemente favorecendo o aleitamento e reduzindo a mortalidade infantil. O acesso a informação se configura uma poderosa ferramenta na busca de resultados satisfatórios acerca do aleitamento materno ${ }^{(5)}$.

Diante do exposto, o estudo foi orientado pela seguinte questão de pesquisa: Como as mulheres primiparas vivenciam o processo de amamentação? Logo, teve por objetivo conhecer as vivências acerca do processo de amamentação, por mulheres primiparas, durante o período de puerpério.

\section{METODOLOGIA}

\section{Tipo de estudo}

Caracterizou-se por um estudo de campo, descritivo, com abordagem qualitativa.

\section{Participantes da pesquisa}

Participaram do estudo nove mulheres que estavam vivenciando o puerpério e sendo assistidas pela equipe da unidade de saúde. A captação das participantes se deu por meio de informações dos enfermeiros da unidade, sendo que o convite ocorreu, conforme as puérperas buscaram o serviço durante o período de pesquisa, caracterizando amostra por conveniência. Como critérios de inclusão, considerou-se ser puérpera primípara, independentemente do tipo de parto e da classificação de risco. Como critério de exclusão se aplicou a idade inferior a 18 anos.

\section{Local do estudo}

O estudo foi desenvolvido no município de Pato Branco, localizado na região Sudoeste do estado do Paraná. O cenário foi uma unidade básica de saúde, referência na assistência à saúde da mulher do município.

\section{Coleta de dados}

A coleta das informações ocorreu entre os meses de maio e junho de 2017, quando foi realizada entrevista semiestruturada individual, por meio de um roteiro elaborado pelas próprias pesquisadoras. A pesquisa foi composta por duas etapas: na primeira, buscou-se identificar algumas questões de caracterização dessas puérperas, como idade, estado civil, escolaridade, renda familiar, tipo de parto, se gestação foi planejada ou não, estratificação do risco gestacional e quantos dias de vida do recém-nascido; a segunda etapa foi constituida por questões orientadas, de acordo com o objetivo do estudo, sendo elas: Como está se sentindo em relação a este período? Comente qual foi a maior dificuldade durante este período. Como enfrentou esse momento? Contou com ajuda de alguém? Durante o pré-natal, conseguiu esclarecer as suas dúvidas sobre a amamentação? Quem lhe orientou? Durante este período, qual o momento que foi mais marcante para você? Poderia descrever o significado dele?

As entrevistas aconteceram no domicílio das participantes. Após a captação das mesmas na unidade de saúde, agendou-se uma data e horário para a entrevista, de acordo com a preferência das participantes. Na data acordada as pesquisadoras compareceram ao domicílio para a entrevista. As entrevistas foram gravadas, mediante a autorização das participantes, buscando assegurar a fidedignidade dos dados. Após, foram transcritas na integra e analisadas.

\section{Procedimento de análise dos dados}

A análise dos dados transcritos se deu por meio da técnica de análise de conteúdo temática, pela proposta operativa(6), onde, em um primeiro momento, buscou-se uma compreensão geral do grupo estudado, e em um segundo momento, buscou-se, os sentidos dos relatos das participantes. Nesta fase, ocorreu a ordenação dos dados, incluindo as transcrições do material previamente gravado, sua releitura e organização dos dados, que foram classificados, realizando-se leitura horizontal e exaustiva dos textos e leitura transversal, fazendo um recorte do material coletado e os separando por 
partes semelhantes, que foram posteriormente discutidas com a literatura.

\section{Procedimentos éticos}

Esse trabalho seguiu as normas preconizadas pela Resolução no 466/2012 ${ }^{(7)}$, do Conselho Nacional de Saúde, relativa à pesquisa envolvendo seres humanos. Obteve aprovação pelo Comitê de Ética em Pesquisa, em maio de 2017, sob número de CAAE: 66879317.6.0000.0116. As entrevistas foram realizadas somente após a assinatura do Termo de Consentimento Livre e Esclarecido pelas puérperas. Foi assegurado o sigilo e anonimato das participantes, identificando-se as entrevistadas por um sistema alfanumérico, composto pela letra $L$ (Lactente), seguido de um numeral.

\section{RESULTADOS}

Participaram do estudo nove puérperas primíparas, com idades entre 18 e 38 anos. Seis delas eram casadas, uma vive com companheiro amasiada e duas solteiras. Em relação à escolaridade, cinco possuem o ensino médio completo, três possuem ensino superior completo e uma é pós-graduada. A renda familiar das entrevistadas esteve entre dois e seis salários mínimos (com base no ano vigente - 2017). Quanto ao tipo de parto, sete cesáreas e dois partos vaginais; sete gestações não planejadas e duas planejadas, dentre elas foi encontrado classificação desde risco habitual até alto risco. Todas realizaram acompanhamento pré-natal.

$\mathrm{Na}$ análise de conteúdo dos relatos emergiram duas categorias temáticas: Os desafios que permeiam a amamentação; e os prazeres acerca da amamentação.

\section{Desafios que permeiam a amamentação}

Os resultados do estudo apontam que a vivência do processo de amamentação é marcada por sentimentos ambíguos. Entre os relatos, afloraram as dificuldades vividas, como a pega do peito no início da amamentação e as fissuras mamilares: Tive dificuldade para amamentar, eu achei mais dificuldade foi para ela pegar no peito mesmo (LI); Logo que ele nasceu a dificuldade foi ele pegar no seio, ele não pegava de jeito nenhum. No hospital ele teve que usar complemento porque ele não estava mamando mesmo, mas depois eu tirei, depois de uma semana eu tirei. Usei o bico de silicone no inicio, para ajudar na pega. Agora está bem tranquilo, agora ele pegou bem e está só no seio (L7)

Vários relatos apontam aos traumas mamilares, principalmente no primeiro dia após o parto ou nos primeiros contatos com a amamentação. Em alguns casos o problema logo foi superado, com orientações quanto a pega correta do recém-nascido. Já em outras situações isso demorou mais, até a puérpera encontrar a forma correta de amamentar: As pri- meiras semanas ali né, saiu um pouco de sangue, machucou, foram uns dez dias assim. O leite começou a vir no terceiro dia, então estava mais dificultoso no início, mas aí veio bastante leite e agora eu tenho bastante, ele está mamando só no peito (L3); No início eu tive dificuldade, meus bicos racharam um monte [...] (L5); No primeiro dia machucou, mas o médico me passou uma pomada e dai deu tudo certo, ela mama bastante e só no peito (L6); Eu tive dificuldade no começo da amamentação, que rachou [o bico do seio], sangrou. Até eu achar a posição, o jeito correto de eu dar o peito para ela foi bem complicado, doía que era uma coisa. É uma coisa também que ninguém te avisa né, que vai doer, todo mundo fala: a é maravilhoso, mas ninguém diz que vai doer, que vai sangrar, que vai ser uma coisa horrorosa. Ninguém comenta, então eu tive essa dificuldade. O que me ajudou bastante também foi a pomada que passaram, e o bico de silicone na primeira semana ajudou bastante, mas eu usei só no início para amenizar a dor, porque chegou um momento que eu não conseguia mais dar para ela [o seio], ai no momento que passou o pior eu tirei [o bico intermediário]. Acho que demorou uma semana, uma semana e meia para as coisas se regularizarem, mas depois que ela pegou bem e que os machucados iniciais cicatrizaram, ai foi embora. Agora está tranquilo, ela está só no seio, e enquanto eu conseguir (L9).

Portanto, por meio dos relatos, observa-se que o processo de amamentação se faz pouco esclarecido durante o pré-natal, especialmente em razão das inúmeras opiniões que elas recebem de terceiros (profissionais, amigos e familiares), levando as mães, em destaque as primiparas, a utilizarem diversos métodos, até que o problema seja solucionado.

\section{Os prazeres acerca da amamentação}

Mesmo diante dos desafios enfrentados no estabelecimento da amamentação, esse momento proporciona sentimentos de satisfação e realização, fortalecendo o vínculo entre mãe e filho: O momento mais marcante é quando vou amamentar (L6); Mas os melhores momentos é quando você amamenta, tem horas que parece que ela para e olha para você, segura sua mão. Eu acho que é o período mais legal, mais interessante, mais marcante mesmo, porque acaba sendo só nós duas (L9).

A maioria das participantes relataram estar em aleitamento materno exclusivo e que pretendem manter, reconhecendo sua importância para a saúde da criança. Somente duas puérperas relataram o uso do complemento com fórmulas infantil na alimentação do recém-nascido.

Também teve casos em que relataram não ter passado por nenhuma dificuldade no processo de amamentar, apesar de relatos de caso de ingurgitamento, que foram facilmente resolvidos com a informação e a atitude correta, de ordenhar o 
seio ingurgitado, evitando problemas maiores. Ainda foi reforçado o fato de receber mais dicas sobre o modo correto de realizar a amamentação, sobre as posições e a pega correta: Eu não tive dificuldade para amamentar, porque comecei a ter leite antes de ganhar ele já, depois que ele nasceu eu recebi mais dicas que pediatra acabou dando, para fazer a pega, dai ele já fez a pega certinha então acabei não sofrendo nada com fissuras. Única coisa é que eu tive bastante leite no começo e dava umas empedradinhas, e ai eu começava a tirar e acabava voltando ao normal. Mas agora não dá nem tempo de empedrar, porque toda hora ele está mamando, e só mama no seio (L8).

Evidentemente a amamentação pode vir a ser um processo muitas vezes doloroso e dificultoso, principalmente se a primípara não recebeu as orientações corretamente ou não obteve ajuda de forma apropriada e confiável, porém o prazer, a satisfação e o benefício que tal ato proporciona, fortalecendo os laços e o vínculo entre mãe e filho, no pesar da balança, compensa todos os sacrifícios encontrados.

\section{DISCUSSÃO}

Os primeiros dias após o parto são elementares para o sucesso da amamentação, pois são de intenso e constante aprendizado para a mãe e o bebê. Muitas mulheres idealizam esse momento e podem vir a se frustrar ao se confrontarem com a realidade ${ }^{(8)}$

Os achados corroboram com outro estudo realizado, que observando a mamada ainda na maternidade, nas primeiras horas pós-parto, revelou que a dificuldade na pega é um dos principais problemas enfrentados durante o início da amamentação ${ }^{(9)}$. Logo, reforça-se a relevância, de identificar essas dificuldades e apoiar a puérpera, visando superar estes obstáculos e atingindo assim o sucesso do aleitamento.

É de suma importância que diante de fatores que dificultam a amamentação, o enfermeiro apoie e forneça informações pertinentes as puérperas, fortalecendo a sua autoconfiança em relação ao aleitamento, beneficiando tanto ela, seus filhos e a sociedade em geral. Além disso, essas ações podem prevenir os principais problemas decorrentes da lactação, reduzindo o desmame precoce, potencializando os fatores que facilitam o aleitamento e intervindo naqueles que dificultam o ato de amamentar ${ }^{(10)}$.

Embora usualmente se identifique alguns impasses relacionados a amamentação, grande parte das novas nutrizes vem a considerar o aleitamento como uma agradável experiência, sustentando o pressuposto que o ato de amamentar, além de todos os benefícios envolvidos, ainda pode ser prazeroso (11).

Referente ás formas de prevenção de agravos, a maneira como a mãe se posiciona e posiciona o bebê para amamentar é muito importante para se realizar a pega correta, para que o recém-nato retire eficientemente o leite da mama e que não machuque os mamilos. Uma posição inadequada dificulta o posicionamento correto da boca do bebê, resultando em uma má pega, que por sua vez dificulta o esvaziamento dos seios, fazendo com que ocasione agitação e choro na criança e podendo levar a uma diminuição da produção do leite, além de deixar a puérpera aflita e a ponto de perder a autoconfiança, com risco de acreditar que o seu leite seja insuficiente ou fraco. A sucção do recém-nascido é um ato reflexo, porém, ele precisa aprender a pega correta a fim de evitar esses males $(8,12)$.

Acerca dos temas explorados envolvendo a amamentação, muitas mulheres referem terem conhecimento acerca do tempo de amamentação exclusiva preconizado, sendo amplamente discutido e informado das mais variadas formas, porém, contendo um baixo conhecimento sobre as possiveis complicações relacionadas ao aleitamento e que podem influenciar nesse tempo de duração ${ }^{(13)}$

Durante as primeiras mamadas e habitualmente no começo das mesmas, a mulher sentir uma discreta dor nos mamilos é comum e considerado normal, apesar de que o fato não deve persistir além da primeira semana. Apresentar muita dor e machucados nos mamilos é bastante comum, porém não é normal, e as causas mais recorrentes de dor ao amamentar são ocasionadas além do posicionamento e pega inadequados, como por sucção não nutritiva prolongada, uso de bicos intermediários, dentre outros. Muitos dos tratamentos para traumas mamilares utilizados rotineiramente, não têm respaldos por estudos de qualidade ${ }^{(8)}$.

Sobre o uso de bicos intermediários, citados por algumas das puérperas, estudo revela que a utilização de qualquer tipo de bico artificial pode ocasionar uma confusão entre bicos no recém-nascido e também favorecer maior incidência de fissuras e até o desmame, isso relacionado à criança. Um desmame precoce ainda pode ser ocasionado pelo fato de ocorrer a fissura mamilar, relacionado as causas maternas ${ }^{(3)}$. Em outra direção, os resultados do estudo apontam a utilização frequente desse acessório no início da amamentação. Essa prática pode representar danos no estabelecimento da amamentação, pois o mesmo pode ser o causador das lesões que venham a causar dor, ao invés de ser o alivio para as mesmas, além de se tornar motivo de confusão para a criança, que pode vir a rejeitar o seio após o contato com outros tipos de bicos que não o da mãe.

Em suma, é durante o pré-natal que se considera o momento ideal para orientar a mulher sobre o aleitamento materno, já que as ações específicas de apoio profissional e acesso a informação adequada, tem configurado taxas mais efetivas na prática de amamentação. O profissional de saú- 
de, em especial o enfermeiro, possui papel fundamental na promoção, proteção e apoio a amamentação, e para desempenhar esse papel, reque além do conhecimento e de habilidades acerca dos aspectos técnicos da lactação, um olhar atento as dimensões emocionais, culturais e a rede social de apoio à mulher (14).

O ato de amamentar vai além de nutrir, é um processo de interação profunda entre mãe e filho, o melhor meio de proporção de afeto e proteção, com repercussões na habilidade de defender o bebê de infecções, no seu desenvolvimento cognitivo e emocional, e em sua saúde no longo prazo, implicando também na saúde física e psicológica materna. Além de tudo, constitui-se a forma mais econômica. É grande seu impacto na promoção de saúde integral do binômio e de toda a família e sociedade(8).

Para ser bem-sucedida na amamentação, a mãe necessita de suporte, dos profissionais de saúde e, principalmente, da sua família e da comunidade. Ela precisa, preferencialmente, estar inserida em um ambiente que a apoie as suas decisões, principalmente se optar por aleitar exclusivamente no seio, pois o incentivo das pessoas que a cercam, sobretudo os companheiros, aos avós da criança e as demais pessoas significativas para a mãe são de grande relevância ${ }^{\left({ }^{8}\right)}$.

A puérpera primípara deve ser cuidada, ouvida e se sentir segura, confiando que seus valores e crenças serão respeitados. Assim, é crucial que a equipe de saúde tenha um olhar minucioso para com as primíparas, promovendo estratégias com uma abordagem dialógica buscando a promoção do processo de empoderamento e pertencimento do ao ato de amamentar ${ }^{(12)}$.

\section{Limitações do estudo}

Embora o estudo demonstre resultados significativos, considera-se como fator limitante o fato do mesmo ter sido desenvolvido em uma única unidade básica de saúde, não contemplando outros cenários de assistência à saúde da puérpera do município.

\section{Contribuições do estudo para a prática}

Os benefícios do estudo se dão de forma indireta, com as contribuições da pesquisa para a assistência de enfermagem no pré-natal e puerpério. As participantes não receberam nenhum benefício de forma direta.

\section{CONCLUSÕES}

A vivência da maternidade pela primeira vez apresenta sentimentos singulares na vida da nova mãe, pois também é um momento apinhado de desafios a serem enfrentados. Dentre as situações narradas, a amamentação se mostrou um evento marcado por sentimentos ambíguos. Entre os relatos sobre as dificuldades enfrentadas no início do processo, a pega inicial do seio materno e os traumas mamilares demonstraram maior relevância.

Para enfrentar as dificuldades relacionadas ao processo de amamentação, a orientação profissional, mostrou-se um efeito positivo no enfrentamento dos eventos adversos ao ato de amamentar, tornando o processo mais prazeroso desde o início e, muitas vezes, livre de dificuldades, as quais, existindo, foram contornadas rapidamente. Para tanto, salienta-se a importância da orientação profissional, que deve estar presente durante o pré-natal, preparando a mulher e a família para o processo de amamentação.

Para além do pré-natal, faz-se necessária a disponibilidade de apoio profissional na maternidade, haja vista que são nos primeiros momentos da amamentação em que se instalam as dificuldades mais frequentes. $\mathrm{O}$ apoio à primigesta neste período irá fortalecê-la em sua totalidade, para que a mesma não saia do hospital com morbidades, que podem vir a abalar sua autoconfiança e comprometer a durabilidade do aleitamento materno exclusivo.

Evidenciou-se que, mesmo diante das adversidades, a amamentação se caracterizou como um momento de reconhecimento entre mãe e filho, e, portanto, um formador de vínculos entre os dois. $\mathrm{O}$ ato de amamentar e nutrir o seu fitho, traz sentimentos de realização plena do papel materno.

\section{Contribuição dos autores}

Concepção e desenho, análise e interpretação dos dados, redação do artigo, revisão crítica, revisão final: Cleunir de Fatima Candido de Bortoli, Jesica Fernanda Poplaski, Paula Roberta Balotin. 


\section{REFERÊNCIAS}

1. Cunningham FG: et al. Obstetricia de Williams. 24르 ed. Porto Alegre: AMGH: 2016.

2. Zugaib M. Francisco RPV, Cançado, SJB. Zugaib Obstetricia. 3a ed. Barueri, SP: Manole; 2016

3. Amaral, R. C. Fatores que contribuem para o desmame precoce e atuação da enfermagem. FACIDER Revista Cientifica, Colider [Internet]. 2016 [cited 2017 jun 20]; (9):1-17. Available from: http://sei-cesucol.edu.br/revista/index.php/facider/ article/view/142/177.

4. Capucho LB, Forechi L, Lima RCD, Massaroni L, Primo CC. Fatores que interferem na amamentação exclusiva. Rev. bras. pesqui. saúde [Internet]. 2017 [cited 2018 Jun 25];19(1): 108-13. Available from: http://periodicos.ufes.br/RBPS/article/ viewFile/17725/12151

5. Oliveira CM. Santos TC, Melo IM. Aguiar DT, Mourão Netto JJ. Promoção do Aleitamento Materno: intervenção educativa no âmbito da Estratégia de Saúde da Fatamento Materno: intervenção educativa no ambito da Estrategia de Saude da Fa-
milia. Enferm. rev. [Internet]. 2017 [cited 2018 Jun 25];20(2):99-108. Available from: http://200.229.32.55/index.php/enfermagemrevista/article/viewFile/16326/12418

6. Minayo, MC S. O desafio do conhecimento: pesquisa qualitativa em saúde. $14^{a}$ ed. São Paulo: Hucitec: 2014

7. Resolução no 466 do Conselho Nacional de Saúde, de 12 de dezembro de 2012 (BR) [Internet]. Aprova as diretrizes e normas regulamentadoras de pesqui(BR) [Internet]. Aprova as diretrizes e normas regulamentadoras de pesqui-
sas envolvendo seres humanos. Diário Oficial da União. 12 dez 2012. [cited 2017 sas envolvendo seres humanos. Diário Oficial da União. 12 dez 2012. [cited 2017
jun 20 ]. Available from: http://bvsms.saude.gov.br/bvs/saudelegis/cns/2013/ res0466_12_12_2012.html

8. Brasil. Ministério da Saúde. Secretaria de Atenção à Saúde. Departamento de Atenção Básica. Saúde da criança: aleitamento materno e alimentação complementar / Ministério da Saúde, Secretaria de Atenção à Saúde, Departamento de Atenção Básica, Brasilia 2a Ed,;2015.
9. Fernandes BGE, Silva VB, Pereira JM, Soares MS, Medeiros Filho RA, Pereira LB, et al. Dificuldades iniciais com a técnica da amamentação e fatores associados a problemas com a mama em puérperas. Rev. paul. pediatr. [Internet]. 2017 [cited 2018 Jun 25]:35(3):265-272. Available from: http://www.scielo.br/scielo.php?scrip$\mathrm{t}=$ sci_arttext\&pid=S0103-05822017000300265\&lng=en.

10. Urbanetto PDG, Gomes GC, Costa AR, Nobre CMG, Xavier DM, Jung BC. Facilidades e dificuldades encontradas pelas puérperas para amamentar. Rev Fund Care dades e dificuldades encontradas pelas puerperas para amamentar. Rev Fund Care
Online. [Internet]. 2018 [cited 2018 Jun 25]:10(2):399-405. Available from: http:// www.seer.unirio.br/index.php/cuidadofundamental/article/view/6060

11. Spindola T, Penha LC, Lapa AT, Cavalcante ALS, Silva JMR, Santana RSC. Periodo pós-parto na ótica de mulheres atendidas em um hospital universitário. Enferm Foco [Internet]. 2017; [cited 2019 Ago 14] 8 (1): 42-46. Available from: http://revista. cofen.gov.br/index.php/enfermagem/article/view/847/364

12. Brasil. Ministério da Saúde. Secretaria de Atenção à Saúde. Departamento de Atenção Básica. Atenção ao pré-natal de baixo risco [recurso eletrônico] / Ministério da Saúde. Secretaria de Atenção à Saúde. Departamento de Atenção Básica. Brasilia, 1. ed. rev. Editora do Ministério da Saúde: 2012.

13. Visintin AB, Primo CC, Amorim MHC, Leite FMC. Avaliação do conhecimento de puérperas acerca da amamentação. Enferm Foco[Internet] 2015 [cited 2019 Ago 14];6(1/4): 12-16. Available from: http://revista.cofen.gov.br/index.php/enfermagem/article/view/570/252

14. Ferreira HLOC, Oliveira MF, Rodrigues EB, Almeida BPC, Aquino OS, Pinheiro AKB. Fatores Associados à Adesão ao Aleitamento Materno Exclusivo. Ciênc. saúde colet. [Internet]. 2018 [cited 2018 Jun 25];23(3):683-690. Available from: https://www. scielosp.org/scielo.php?script=sci_arttext8pid=S1413-81232018000300683\# 